\title{
The Development of Students' Mathematical Argumentation in a Primary Classroom
}

\author{
Pi-Jen Lin' \\ 'National Tsing Hua University (NTHU), Hsinchu - Taiwan
}

\begin{abstract}
The Development of Students' Mathematical Argumentation in a Primary Classroom ${ }^{1}$. The use of valid argument does not come naturally. It is acquired only through practice. This study was accomplished to provide students intended opportunities of engaging activities for launching argumentation in primary classrooms. The focus of the paper is how argumentation was evolved when students engaged in the conjecturing incorporated into regular mathematics instruction over two consecutive years. Working with a group of 6 teachers was to develop conjecturing tasks and pedagogical strategies to support them in teaching, and then to enhance the quality of students' argumentation when 24 students were in grades 3 and 4 . The collected data mainly consisted of conjecturing tasks, audio - and video - taped recordings of classroom observations, and students' worksheets. Results indicate that the evolution of argumentation was identified in two aspects: the characteristics and the quality of the argumentation.
\end{abstract}

Keywords: Argumentation. Conjecturing. Task Design. Primary Classroom.

RESUMO - O Desenvolvimento da Argumentação Matemática por Estudantes de uma Turma do Ensino Fundamental. O uso de argumentos válidos não surge de maneira espontânea, sendo adquirido apenas com a prática. Este estudo foi desenvolvido para proporcionar, aos estudantes, oportunidades planejadas de atividades motivadoras para desencadear a argumentação em turmas do Ensino Fundamental. O foco do artigo é compreender como a argumentação evoluiu quando os estudantes envolvidos na conjectura a incorporaram ao ensino regular de matemática durante dois anos consecutivos. Trabalhou-se com um grupo de 6 professores para desenvolver tarefas de conjectura e estratégias pedagógicas para apoiá-los no ensino e, com isso, melhorar a qualidade da argumentação de 24 estudantes do $3^{\circ} \mathrm{e}$ do $4^{\circ}$ ano. Os dados coletados consistiram principalmente de tarefas de conjectura, gravações em áudio e vídeo de observações em sala de aula e das folhas de trabalho dos estudantes. Os resultados indicam que a evolução da argumentação foi identificada por dois aspectos: as características e a qualidade da argumentação.

Palavras-chave: Argumentação. Conjectura. Planejamento de Tarefa. Ensino Fundamental.

Educação \& Realidade, Porto Alegre, v. 43, n. 3, p. 1171-1192, July/Sept. 2018.1171 http://dx.doi.org/10.1590/2175-623676887 
The Development of Students' Mathematical Argumentation in a Primary Classroom

\section{Introduction}

Many studies have emphasized on the importance of argumentation (Stylianides; Bieda; Morselli, 2016; Kim; Hand, 2015), since effective argumentation skills are essential for conceptual understanding and good communication. Accumulating studies and reform documents have recommended that students should have early opportunities to make conjectures, explore the truth of their conjectures, use counterexamples, justify their conclusions, communicate them to others, and respond to the arguments of others (e.g., Common Core State Standards Initiative, 2010; Hanna; Villiers 2012; National Council of Teachers of Mathematics, 2000). However, teaching argumentation in classrooms has been slow when a number of challenges exist for both teachers and students. For students at various educational level, they tend to face serious difficulties in argumentation. For instance, a number of empirical studies have addressed the difficulties secondary students face when they justify their solutions (Ko, 2010; Stylianides; Stylianides; Philippou, 2007). In-service teachers do not believe that a single counterexample is sufficient to refute a universal statement (Barkai; Tsamir; Tirosh; Dreyfus, 2002).

For teachers never being taught argumentation in their young ages, they may feel unprepared to teach argumentation (Gabel; Dreyfus, 2013; Reid; Zack, 2011). Many elementary school teachers do not feel they have the mathematical background to teach argumentation or even a clear idea of what argumentation looks like. Teachers themselves often face similar difficulties with argumentation as their students. As Yackel and Hanna's emphasis (2003) on the most challenging goal for mathematics educators in helping students the development of argumentation is "[...] to design means to support teachers in developing forms of classroom mathematics practice that foster mathematics as reasoning and that can be carried out successfully on large scale" (Yackel; Hanna, 2003, p. 234). This indicates that teachers need to be supported in acquiring new experience or new knowledge about teaching argumentation. The data presented in the study was part of a project on mathematical argumentation involving six primary school teachers over three years. The aim of the project is designed to support teachers in designing tasks and enacting them in classrooms at early grade levels that mathematical argumentation takes place. When designing tasks for conjecturing, teachers had to follow the instructional objectives and carefully plan how to include conjecturing activities in routine mathematics lessons. This paper draws on the data from a classroom in the first two years of the project.

This study taking conjecturing as an instructional approach is based on conjecturing to be able to intrigue argumentation (Lin; Tsai, 2016; Stylianides, 2009). The conjecturing is a process of observing a finite number of cases, identifying patterns, formulating claims/conjecturing, validating the conjectures, generalizing the conjectures, and justifying the generalization (Cañadas et al., 2007). According to Styli-

1172 Educação \& Realidade, Porto Alegre, v. 43, n. 3, p. 1171-1192, July/Sept. 2018. 
anides (2009), a conjecture is defined as a reasoned hypothesis about a general mathematical relation based on incomplete evidence. The term of hypothesis indicates a level of uncertainty about the truth of a conjecture. The uncertainty leading to further action is needed for its acceptance or rejection. Thus, conjecturing is more likely to inaugurate classroom discourses that argumentation takes place. In this study, we distinguish argumentation from arguments. Arguments are the components data, claims, warrants, backings, qualifier, and rebuttals and that contribute to the content of an argument (Toulmin, 1958), whereas argumentation refers to the process of assembling these components (Knipping, 2008).

This study aimed to explore how students' argumentation was developed across different mathematics domains (arithmetic, measurement, and geometry). The research question to be answered was: How do young students develop argumentation when they are engaged in conjecturing tasks incorporated into the mathematical contents through regular instruction in a primary classroom over two consecutive years?

\section{Theoretical Framework}

\section{Argumentation}

The curriculum reforms in mathematics education have given rise to an emerging body of research on teaching and learning of argumentation at different grade levels, particularly classroom-based research (Stylianides; Bieda; Morselli, 2016; Stylianou; Blanton; Knuth, 2011). Even primary students are able to share their mathematical ideas, explore and discuss the patterns they observe, and articulate their generalizations (Keith, 2006; Maher, 2011; Schifter, 2011). When children are placed in supportive learning environments, the idea of justification can come naturally to them (Maher; Martino, 1996). The supports could be questioning, types of problems or tasks, the instructor, and social norms of argumentation. However, previous studies did not mention what tasks are likely to support teachers to enhance students' argumentation. Stylianides, Bieda and Morselli (2016) called for more studies on students' understanding of argumentation in elementary school and in other domains beyond geometry.

Argumentation involves ascertaining and persuading. Ascertaining is the process that an individual uses to remove individual's doubts, whereas persuading is the process of removing others' doubts (Harel; Sowder, 2007). In argumentative learning, understanding is more likely to occur when one requires to explain, elaborate, or defend one's position to others (Makar; Bakker; Ben-Zvi, 2015). Argumentation is seen as a social process, in which two or more individuals engaging in a mathematical discourse. Primary students' thinking expressed in classrooms does not follow the patterns of formal mathematics, but these patterns are important to the future development of their thinking (Hanna; Vil-

Educação \& Realidade, Porto Alegre, v. 43, n. 3, p. 1171-1192, July/Sept. 2018.1173 
liers 2012). Thus, facilitating the use of argument would require a shift in the nature of the discourse in mathematics lessons. In an expected classroom where the young students develop skills of persuasive arguments, instead of being an audience for the teachers' reasoning, but needs to provide students the opportunities to learn such argumentation.

Even though teachers are aware of the importance of argumentation in mathematics classroom, they still struggle to implement it. The use of valid argument does not come naturally and is acquired only through practices (Kuhn, 1991). Not all problems lead to conjecturing, and different problems lead to different kinds of conjecturing (Cañadas et al., 2007). This implies that teachers play a critical role in designing tasks to boost students' argumentation in mathematical classroom.

\section{Relationship Between Argumentation and Conjecturing}

Argumentation is highly related to conjecturing. Conjecturing initiates generalization, while justification involving in argumentation tests the truth of conjecturing. Mathematical knowledge is derived from an iterative process of through conjecturing, testing, refutation, revising, re-testing, and to justification. Conjecturing is involving in doing mathematics (Mason; Burton; Stacey, 1987; Pólya, 1968). Stylianides (2009) addresses the relationship between conjecturing and argumentation. He defines a conjecture as "[...] a reasoned hypothesis about a general mathematical relation based on incomplete evidence. The term 'reasoned' highlights the non-arbitrary character of the hypothesis. The term 'hypothesis' indicates a level of uncertainty about the truth of a conjecture and denotes that further action is needed for its acceptance or rejection" (Stylianides, 2009, p. 264). According to Stylianides, making conjectures is a problem solver's formulation of the claims or their hypotheses beyond a domain of cases. Making conjectures is also the precursor of identifying patterns; generalizing conjectures, and patterns can generate conjectures, which in turn can give rise to the development of justification.

The relationship between conjecturing and argumentation described in Figure 1 is the framework of this study for designing tasks and enacting conjecturing in classrooms at primary school. This framework makes the connection of conjecturing suggested by Cañadas and Castro (2005) and components of argumentation suggested by Toulmin's (1958). Cañadas and Castro's (2005) seven stages were adapted into five stages for this study, consisting of constructing cases, formulating conjectures, validating the conjectures, generalizing, and justifying the generalization. Toulmin's (1958) main components of argumentation consist of data, claims, warrants, backings, qualifiers, and rebuttals. Data are the foundations on which the argument is based, as well as the evidence relevant to the claim. Claims are the assertions about what exits or values people hold, leading to the conclusions which the arguer wishes to arrive at. Warrants refer to the statements that explain the

1174 Educação \& Realidade, Porto Alegre, v. 43, n. 3, p. 1171-1192, July/Sept. 2018. 
relationship of the data to the claim. For example, appealing to a rule, defining or making an analogy. Qualifiers are special conditions under which the claim holds true. Backings are the underlying assumptions that are often not made explicit. Rebuttals are the statements that contradict either the data, warrant, backing or qualifier of an argument.

Figure 1 - The Framework of the Research Design of the Study

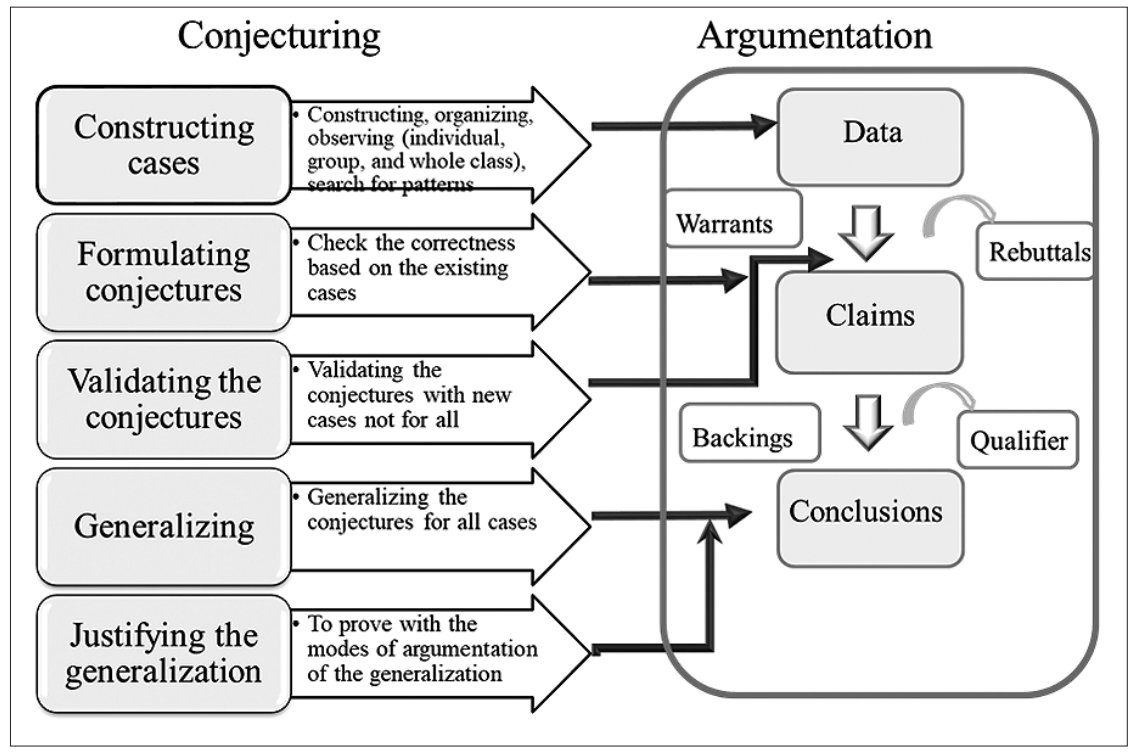

Source: Author's elaboration (2017).

The components of argumentation to be initiated at each stage of conjecturing is described in Figure 1. Cañadas and Castro's (2005) seven stages does not include constructing cases, but the cases created by students themselves are more likely to motivate them to observe and search for patterns. Harel (2008) suggests that intellectual need, selfgenerated cases instead of cases given by teacher - arouse more curiosity and interested to observe and look for patterns. Thus, constructing cases is added into the first stage of conjecturing including Cañadas and Castro's stages of observing cases and organizing cases. Constructing cases, the first stage of the conjecturing, corresponds to the data of argumentation. Formulating conjectures is the second stage including Cañadas and Castro's stages of searching for patterns and generating conjectures. These conjectures were likely to develop mathematical properties as target conclusions. The warrants occur in group discussions for sharing and checking the conjectures the students proposed in second stage of conjecturing. The cases constructed in the first stage contributed to the data as an argument for or against claims; the conjectures to be formed in the second stage corresponded to the claims

The last three stages of conjecturing in the framework - included validating the conjectures, generalizing, and justifying the generaliza-

Educação \& Realidade, Porto Alegre, v. 43, n. 3, p. 1171-1192, July/Sept. 2018.1175 
tion - corresponded to Cañadas and Castro's last three stages, respectively. Validating conjectures with new or more cases, the third stage, is a process of making claims and leading to the target conclusions. Refutation, warrants, backings, qualifiers are involving in the validation stage. The fourth stage is to generalize the conjectures for all cases. The qualifier as an element of argumentation occurs in the third and fourth stages of conjecturing. The premise of a claim is proposed in the third and the fourth stage. Justifying the generalization, the final stage of conjecturing, corresponds to the target conclusions. Deductive reasoning and backings are involved in the justification stage of the conjecturing.

\section{Analytical framework of Argumentation}

Toulmin's (1958) model of arguments has been increasingly drawn on by studies in education to provide a template for informal arguments in classrooms and individual students' proving processes (e.g., Pedemonte, 2007; Osborne; Erduran; Simon, 2004). The analysis of students' arguments has been concentrated on the content and the structure of argument (Inglis; Mejia-Ramos; Simpson, 2007; Knipping, 2008). Toulmin's (1958) scheme can be used to assess the structure of arguments, but it does not lead to judgments about their correctness and it also presents argumentation in a decontextualized way with no recognition given to the interactional aspects of an argument as a speech event. Hence, argumentation that occurs in classrooms cannot be analyzed using formal logic (Knipping, 2008). To capture the collective nature of arguments in classrooms and see the progress of students' argumentation over time, we need to find an analytical framework to identify argumentation.

We adapted Knipping's (2008) analytical process as a tool for analyzing argumentation structure in group and whole-class discourse. A three-stage process of analyzing argumentation is proposed: (1) reconstructing the sequencing and meaning of classroom talk; (2) analyzing arguments and argumentation structures; the sequence of arguments with different elements formed an argumentation stream: different functions including data, warrants, backings, rebuttals and conclusions, were represented with different symbols (circle, rhombus, or rectangle). The young students with weak mathematics knowledge and little experience on group discussion, so that we added teachers' guide in the structure to see when and what teachers give supports for students; and (3) comparing local and global argumentation structures.

Knipping's (2008) analytical framework with three stages of analyzing students' collective argumentation in classrooms do not judge which argumentation structures is better than the other. After analyzing the argumentation structures, in order to examine the development of students' argumentation, we need to develop a criterion to assess the quality of an argumentation. The criteria of assessing the quality of argumentation for the study is adapted from Osborne, Erduran and Simon

1176 Educação \& Realidade, Porto Alegre, v. 43, n. 3, p. 1171-1192, July/Sept. 2018. 
(2004) framework for assessing the quality of argumentation. Two criteria are proposed: one criterion concerns whether an argument contains data (including reasons and grounds), warrants, or backings, and developing rational thought relying on the ability to justify and defend one's beliefs. The arguments are ranked as lower level as those consisting of a claim only. The other is whether an argument involves rebuttals or not. In this framework, arguments with rebuttals are ranked into better quality compared to those without, because the ability to use rebuttals is the most complex skill (Kuhn, 1991). The rebuttal involves not only to understand others' thinking, but also to raise different opinions to refute others' thinking. Osborne, Erduran and Simon (2004) ranks the quality of argumentation with five levels. Levels 1 and 2 do not involve rebuttals, whereas Level 3, 4, and 5 do. The three higher levels are therefore determined by the arguments with rebuttals. Levels 3, 4, and 5 are distinct with the frequency of the use of rebuttal.

\section{Research Method}

\section{Participants and Context}

The data derived from a large database of a 3-years teacher professional development project. The goal of the project is to develop teachers' skills in designing conjecturing tasks for initiating argumentation and see how students' argumentation was developed when the teachers enacted the tasks in primary classrooms. Six teachers with 5 to 20 years of experience were willing to adopt an innovative instruction for improving students' learning in mathematics. The size of each of the six classes from grade 3 to 5 was ranged from 18 to 25 students. The 24 students in Jing's class, who had no previous experience of engaging in conjecture, were the participants of this study over two consecutive years from grade 3 to grade 4 . Due to length constraints, we only report in this article one of the six classrooms selected for two reasons: (1) to explore how argumentation can develop via conjecturing, thus, to examine what instruction, rather than typical teaching practice, might be considered successful; (2) only Jing was teaching the students who were in the same class from grade 3 to 4 , but other teachers were teaching the students who were not in the same class over the two consecutive years.

\section{Designing Tasks for Conjecturing}

Over the course of the two years, we did not provide Jing a detailed plan of how she might carry out the tasks; instead, we provided her ideas for facilitating her development by encouraging her to take ownership in designing her individual tasks and pedagogy. The weekly meetings served to introduce Jing with the theoretical perspectives, a possible format for conjecturing task, and what a lesson of argumentation looks like. The format of a conjecturing task included the five stages of conjecturing and advice to carry out the tasks in accordance with the five

Educação \& Realidade, Porto Alegre, v. 43, n. 3, p. 1171-1192, July/Sept. 2018.1177 
stages of conjecturing that inspire argumentation. Jing was encouraged to incorporate conjecturing into mathematical contents scheduled in textbooks as many as possible without taking up extra hours.

Six of the total 16 tasks enacted in Jing's class throughout the two years were selected for reporting in this article for three reasons. First, the 6 tasks enacted in lessons were observed. Second, the data collection should be as complete as possible. Third, the selection was made across various topics and distribution in different periods in school year. Three tasks of the 8 tasks enacted in the third grade included topics of areas, perimeters, and number division, whereas the other three selected tasks from the 8 tasks enacted in the fourth grade were on volume, triangles, and quadrilaterals. The topic of the perimeter of a rectangle is presented as an example (see Table 1).

\section{Table 1 - A Conjecturing Task of the Perimeter of a Rectangle}

\begin{tabular}{|c|c|}
\hline $\begin{array}{l}\text { Task: To recognize the perimeter that keeps the same } \\
\text { if a small square is cut at the corner of a rect- } \\
\text { angle. }\end{array}$ & $\begin{array}{l}\text { Five stages of conjectur- } \\
\text { ing }\end{array}$ \\
\hline $\begin{array}{l}\text { (a) Cut a small square off from an A4 paper and shade it. } \\
\text { (b) Put the paper you shaded together in a group. How } \\
\text { many ways were the paper cut in your group? }\end{array}$ & $\begin{array}{l}\text { Constructing individual } \\
\text { cases, } \\
\begin{array}{l}\text { Organizing \& observing } \\
\text { the cases }\end{array}\end{array}$ \\
\hline $\begin{array}{l}\text { (c) What did you discover after cutting a square off from } \\
\text { the A4 paper? Write it down. } \\
\text { (d) Do you have any other ways such that its perimeter } \\
\text { keeps the same, or longer, or shorter? } \\
\text { (e) How did you cut such that the new shape always keeps } \\
\text { the same perimeter, shorter, or longer comparing to } \\
\text { the original one? }\end{array}$ & $\begin{array}{l}\text { Looking for patterns } \\
\text { Formulating conjectures }\end{array}$ \\
\hline (f) How do you validate your conjectures? & $\begin{array}{l}\text { Validating the conjec- } \\
\text { tures }\end{array}$ \\
\hline (g) Does each of your conjectures work for all cases? & $\begin{array}{l}\text { Generalizing the con- } \\
\text { jectures }\end{array}$ \\
\hline $\begin{array}{l}\text { (h) How do you convince others that your conjectures } \\
\text { are true? }\end{array}$ & $\begin{array}{l}\text { Justifying the general- } \\
\text { ization }\end{array}$ \\
\hline
\end{tabular}

\section{Enacting Conjecturing for Initiating Argumentation}

Through weekly meetings, we also provided advice about how to enact conjecturing tasks in classrooms to emphasize mathematical argumentation through the use of warrants for or against a conjecture. The weekly meetings also provided Jing a reflection on how well the tasks worked and helped her in identifying when and what students' arguments occurred. It was clear from such discussions that Jing had the opportunity to reshape her own views.

A typical lesson of Jing's enacting conjecturing for initiating argumentations was described as follows. In the first stage for constructing 
cases, Jing preferred to ask students to construct cases individually. It was not enough to find a pattern from a few cases, so they came together in groups of 4 . Then followed by the second stage, students worked individually to realize a pattern and form conjectures based on the set of cases. The individual works more likely have various conjectures, including accidental ones, beyond teacher's anticipation. The individual's conjectures were jotted down on A3 paper; and this was followed by group discussions to share and check if the conjectures were correct. We observed that the conjectures students made were only based on existing cases, true only for several existing cases, and sometimes refuted by other students in this stage. In addition, students' language was frequently modified into mathematical language through group discussions. Then, Jing invited students to display their conjectures on the blackboard and report to the whole class.

In the third stage, Jing asked her students to classify various conjectures into several categories. The conjectures in each category were sequenced for validating their truth with a new case. The uncertainty of the conjectures in each category was checked by existing cases and validating by a new case beyond the existing cases. Warrants, backings, rebuttals and qualifiers could be involved in the process of validating. To make the conjectures lead to target conclusions, Jing asked students: Does each of your conjectures work for all case? The premise of a conjecture true for all cases was proposed. Generalizing the tentative conjectures, Jing asked students whether the validated conjectures were true for all cases or not. When a conjecture to be true is specified a special condition, a qualifier as an argumentation component will be involved in the stage of generalization. In the final stage of justification, Jing asked her students to give reasons to justify their conjectures by asking them: How do you convince your friends that your conjectures are always true? The deductive reasoning based on what the individual student has learned is commonly obtain in the stage of justification. Warrants and backing could also be involved in the final stage. At this point, it is worth noting that the distinction between argument and argumentation has been drawn in this study, the elements including data, conjectures/claims, warrants, backings, rebuttals, and qualifiers form the content of an argument. The argumentation is the process of assembling the elements.

\section{Data Collection}

The data reported in the paper consist of 6 conjecturing tasks, 12 videotaped lessons, and 12 students' worksheets from individuals and groups. Six video recorders simultaneously videotaped individual small groups and together as a whole class in a classroom at a time. The videos of small groups were used for analyzing the local augmentation structures.

Educação \& Realidade, Porto Alegre, v. 43, n. 3, p. 1171-1192, July/Sept. 2018.1179 


\section{Analyzing the Structures of Argumentation}

The characteristics and the quality of argumentation built on the structures of argumentation were identified in two steps: (1) to draw the argumentation structures by systematically analyzing elements of arguments; and (2) to compare the argumentation structures drawn from the six tasks enacted in the classroom. First, argumentation structures were analyzed to reconstruct the sequences and meanings of conversations. Second, arguments and argumentation structures were analyzed. Third, local argumentations were compared by analyzing and classifying the functions of the elements, and global argumentation structures were compared according to overall structures.

Six argumentation streams (ASi, $i=1$ to 6 ) but only three argument streams (AS4, AS5, and AS6) led to the target conclusion $C$ to which the remaining argumentation structures were disconnected, as Figure 2.

Figure 2-Argumentation Structure of the Perimeter of a Rectangle

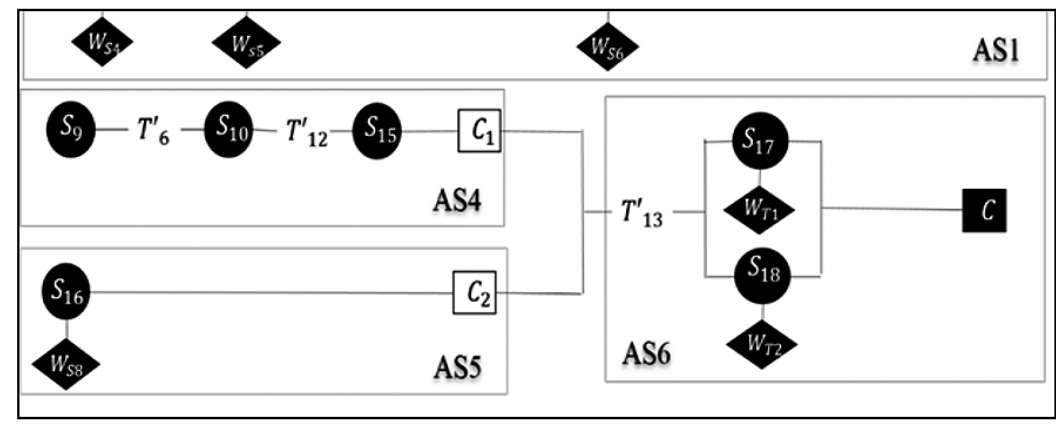

Note: Wi: the $\mathrm{i}^{\text {th }}$ students' warrant

$\mathrm{Ri}$ : the $\mathrm{i}^{\text {th }}$ students' refutation

Ti: the $\mathrm{i}^{\text {th }}$ teacher's intervention

Source: Author's elaboration (2017).

Figure 2 only shows part of the structures of the collective argumentation with respect to the perimeter of rectangle in classroom discourse. Different functions of the arguments, including data, warrants, backings, and conclusions, were represented with different symbols (circle, rhombus, or rectangle) (see Figure 2). The refutation could be initiated from students or the teacher $\left(\mathrm{W}_{\mathrm{Ti}}\right.$ or $\left.\mathrm{W}_{\mathrm{Si}}\right)$. A conclusion $(\mathrm{C} i)$ can be a tentative (white rectangle) or a target conclusion (black rectangle). The sequence of arguments with different functions form an argumentation stream (ASi).

The two tentative conclusions, $\mathrm{C} 1$ and $\mathrm{C} 2$, became target conclusion $C$ in stream AS6 which were drawn from the episode as follows:

286T: This rectangular paper doesn't have any numbers on it. Can you tell me why the perimeter divided by 2 equals the addition of the length and the width? Where is its perimeter?

1180 Educação \& Realidade, Porto Alegre, v. 43, n. 3, p. 1171-1192, July/Sept. 2018. 
287S: (Motions to the peripheral of the paper)

288T: Only one time around? Then why does perimeter divided by 2 equals length plus width? ( $\left.\mathrm{T}^{\prime}{ }^{\prime}\right)$

289S: When you divide it by two, then it's these. (using a finger to point out the place where the sum of the length and the width are). $\left(\mathrm{S}_{17}\right)$

290S: Then, there are two sets. $\left(\mathrm{S}_{17}\right)$

291S: The perimeter divided by 2 is equal to a half $\left(\mathrm{S}_{17}\right)$.

294T: Where is the half of the perimeter? $\left(\mathrm{S}_{17}\right)$

295S: The sum of the length and the width.

296T: What does it mean the other way around?

297S: The length plus width equals half of the perimeter, so when you multiply (the sum) by 2 , you will get the perimeter $\left(\mathrm{S}_{18}\right)(\mathrm{Cl})$

For generalizing the two tentative conclusions $\left(\mathrm{C}_{1}\right.$ and $\left.\mathrm{C}_{2}\right)$ (see Figure 2), Jing expected students to use a statement instead of numerals to describe the way to find the width when the perimeter and the length were given, thus she gave the students an A4 paper without giving them the size of its length and width as the warrants $\left(\mathrm{W}_{\mathrm{T} 1}\right.$ and $\left.\mathrm{W}_{\mathrm{T} 2}\right)$ (line 286), seen in the following episode. She then asked them three guiding questions: $\left(\mathrm{T}_{13}{ }_{13}\right)$ (see lines 286, 288, and 296 below) from which two conjectures - The perimeter divided by 2 is equal to a half $\left(\mathrm{S}_{17}\right)$ (lines 289, 290, and 291) and The length plus the width equals half of the perimeter, so when you multiply by 2 you will get the perimeter $\left(\mathrm{S}_{18}\right)$ (line 297) - were derived.

\section{Analyzing the Characteristics and Quality of Argumentation}

The characteristics of argumentation were coded according to the warrants, backings, refutation, and teacher's guidance displayed in an argumentation structure. Initially, Jing's students were not used to engaging in conjecturing, hence, they required her guidance. Each component was ranked from 0 to 3 . The rubrics of each rank was described in Table 2. The warrants used by primary students were not useful or efficient, hence they were ranked into four levels depending on the degree of being valid. The higher rank stands for higher quality of argumentation. As Osborne, Erduran and Simon's (2004) level of argumentation, arguments consisting of simple claim is ranked at lower level than those consisting of claims with either data, warrants, or backings. Thus, complements of an argumentation were ranked into four levels depending on the complexities and varieties of components involved in an argumentation structures. The tentative conjectures/claims collected from primary students with weak mathematical knowledge were not ensured relevant to mathematics concepts or mathematical properties. The higher quality of initial conjectures depends on the degree of relevant to mathematics, the use of succinct mathematical language, and their potentiality to lead to the conclusion, as target of instructional objectives of a lesson. 
Table 2 - Rubrics of Assessing the Quality of Argumentation

\begin{tabular}{|c|c|c|c|c|}
\hline $\begin{array}{c}\text { Level } \\
\text { Component }\end{array}$ & Level 0 & Level 1 & Level 2 & Level 3 \\
\hline $\begin{array}{l}\text { Accuracy of } \\
\text { the warrants }\end{array}$ & no warrant & irrelevant & plausible & valid \\
\hline $\begin{array}{l}\text { Types of rebut- } \\
\text { tals }\end{array}$ & no rebuttal & $\begin{array}{l}\text { against one } \\
\text { warrant }\end{array}$ & $\begin{array}{l}\text { against more } \\
\text { than one war- } \\
\text { rant }\end{array}$ & $\begin{array}{l}\text { against an in- } \\
\text { valid rebuttal }\end{array}$ \\
\hline $\begin{array}{l}\text { Complements } \\
\text { of the compo- } \\
\text { nents }\end{array}$ & claims only & $\begin{array}{l}\text { claims + war- } \\
\text { rants }\end{array}$ & $\begin{array}{l}\text { claims + war- } \\
\text { rant +a back- } \\
\text { ing/rebuttal }\end{array}$ & $\begin{array}{l}\text { claims + war- } \\
\text { rant + more } \\
\text { than one back- } \\
\text { ing/rebuttal }\end{array}$ \\
\hline $\begin{array}{l}\text { Validity of } \\
\text { initial claims } \\
\text { leading to } \\
\text { conclusion }\end{array}$ & $\begin{array}{l}\text { irrelevant } \\
\text { mathematics }\end{array}$ & $\begin{array}{l}\text { relevant math- } \\
\text { ematics only }\end{array}$ & $\begin{array}{l}\text { no precise } \\
+ \text { relevant } \\
\text { mathematics + } \\
\text { generalization }\end{array}$ & $\begin{array}{l}\text { precise + rel- } \\
\text { evant math- } \\
\text { ematics }+ \\
\text { generalization }\end{array}$ \\
\hline
\end{tabular}

Source: Author's elaboration (2017).

The rebuttals were identified with four levels depending on the use of the refutation. The highest Level 3 is the refutation against an invalid rebuttal. The use of refutation is ranked highest level when the refutation is used for against an invalid rebuttal. It involves not only identifying the rebuttal unable to refute a warrant but also need to figure out to refute the invalid rebuttal. For instance, a student (S7) offered a false isosceles triangle with $90^{\circ}, 20^{\circ}, 20^{\circ}$ for refusing his disagreed a true conjecture The sum of a triangle is $180^{\circ}$. His invalid rebuttal was refused immediately by several students in whole classroom discussion. One student (S20) refused the invalid rebuttal with The three angles $90^{\circ}$, $20^{\circ}, 20^{\circ}$ cannot form a triangle.

Identifying the level of each component was immediately followed by counting the frequencies. For instance, the argumentation structure streams A4, A5, and A6 as part of argumentation structure the perimeter of rectangle in Figure 2 was comprised of 6 conjectures (Si), 3 of which had warrants, and 3 had teacher's guidance. Based on the structures in Figure 2, the accuracy of the two warrants $\left(\mathrm{W}_{\mathrm{T1}}, \mathrm{W}_{\mathrm{T} 2}\right)$, given by the teacher rather than by students, was not counted. The quality of the other three components were counted in the same way. To increase the reliability of the analysis, each argumentation of the tasks was coded by two graduate students who independently read all the episodes, and then met to compare their codes and resolve their differences. Finally, the author joined in their analysis of the comparison of local and global argumentation structures. 


\section{Research Results}

\section{Characteristics of Argumentation Students Made}

Figure 3 displays the characteristics of argumentation in the six topics with four components: conjectures, rebuttals, backings, and teacher's guidance. The qualifiers were not displayed in Figure since only two frequencies were used in the Jing's class.

Figure 3 suggests three trends. First, argumentation discourse did occur in the conjecturing lessons and had been improved from grade 3 to grade 4 . Both graphs for the frequencies of rebuttals and backings go up from grade 3 to grade 4 , whereas the graph of teacher's guidance goes down. The graph for conjectures also goes up from grade 3 to grade 4 .

Figure 3 - Development of the Characteristics of Students' Argumentation

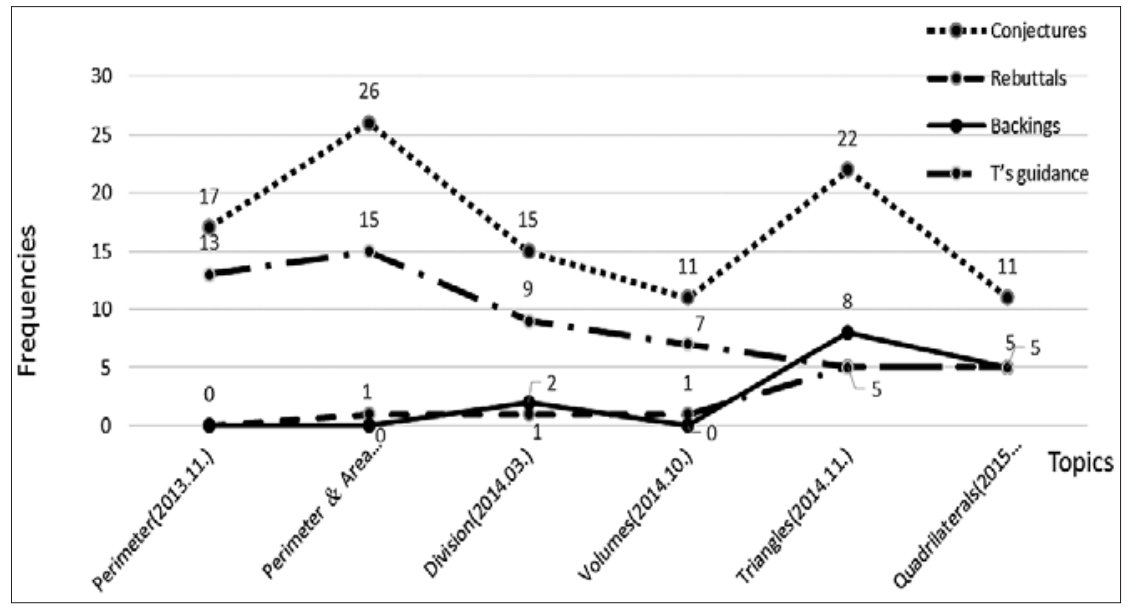

Source: Author's elaboration (2017).

However, for the conjectures, $10 / 17$ (58.8\%), 18/26 (69.2\%), 10/15 (66.7\%), 8/11 (72.7\%), 17/22 (77.3\%), 10/11 (90.9\%) were supported by the warrants. The percentage of the conjectures with warrants increased from $58.8 \%$ to $70 \%$ in grade 3 and from $72.2 \%$ to $90.9 \%$ in grade 4 . These results indicated that students' ability to make warranted conjectures instead of unwarranted ones was progressed via their engagement in conjecturing. The warrants used by the students in grade 3 were the examples they had constructed, whereas the warrants used by the students in grade 4 were based on their prior knowledge. For instance, one obtuse angle only for an obtuse triangle was used by the fourth-graders as the warrant for supporting their conjecture that the sum of three angles a triangle is $180^{\circ}$. When asked to explain how they formulated the conjecture (length + width $) \div 2=$ perimeter, the third graders used a set of cases in the table $(5+4,18 ; 1+8,18 ; 3+6,18)$ that they constructed as the warrant.

Educação \& Realidade, Porto Alegre, v. 43, n. 3, p. 1171-1192, July/Sept. 2018.1183 
Second, the graphs of the argumentation in Figure 3 show that the students were more frequently formulating conjectures than refuting disagreed conjectures in both grades 3 and 4 . The students' conjectures formulated in their third grade were trivial facts relying on the superficial numerals irrelevant to mathematical properties, whereas those in their fourth grade had been enhanced to being relevant to mathematical relationships or properties but without precise mathematical language for conjectures. One possible factors for students making the progress was teacher's questioning. As we observed, students were asked the question: what have you discovered in alignment with the cases you constructed? in the beginning of the study. It was then followed by the questions: what mathematical relations have you discovered in alignment with the cases you constructed? and what new or creative mathematical relations have you discovered in alignment with the cases you've constructed? at the end of the first semester in the third grade.

Figure 3 shows a consistent pattern that the students seldom utilized counterexamples against disagreed claims or backings for defending their warranted claims. Additionally, they were almost unaware of using the backings in supporting their conjectures. A possible reason is that the students had weak mathematical knowledge in new topics; this was evidenced by their more frequent use of backings in supporting the conjectures on triangles and quadrilaterals they had already learned in their grade 3.

Third, the frequencies of teacher's guidance decreased from grade 3 to grade 4 , by about $50 \%$ on average (see Table 3). The teacher's guidance was for evoking argumentation, revising incomplete conjectures, and generalizing a conjecture to all cases. For instance, Jing encouraged students to use complete mathematical language for describing the relationship among the perimeter, width, and length of a rectangle by asking students: So what did you find out? Add the length and the length, then multiply by 2, what does that equal? Students were able to state a conjecture for all cases by using the universal quantity such as for any, for all, or using the term as long as for a premise of the conjecture, and the qualifier as an element of argumentation. 
Table 3 - Functions of Teacher's Guidance in the Six Topics Enacted over two Consecutive Years

\begin{tabular}{|c|c|c|c|c|c|}
\hline \multicolumn{2}{|r|}{ Components } & \multirow{3}{*}{$\begin{array}{l}\text { Teacher's } \\
\text { guidance }\end{array}$} & \multicolumn{3}{|c|}{ Function } \\
\hline \multirow{2}{*}{\multicolumn{2}{|c|}{ Topics }} & & $\begin{array}{l}\text { To complete } \\
\text { conjectures }\end{array}$ & $\begin{array}{c}\text { To revise } \\
\text { conjectures }\end{array}$ & $\begin{array}{c}\text { To evoke } \\
\text { argumentation }\end{array}$ \\
\hline & & & Freq. (\%) & Freq. (\%) & Freq. (\%) \\
\hline \multirow{3}{*}{ 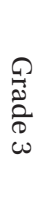 } & $\begin{array}{l}\text { Perimeter } \\
(11 / 2013)\end{array}$ & 13 & $4(30.8)$ & 7 (53.8) & $2(15.4)$ \\
\hline & $\begin{array}{l}\text { Perimeter \& } \\
\text { Area }(01 / 2014)\end{array}$ & 15 & 7 (46.7) & 5 (33.8) & $3(20.0)$ \\
\hline & $\begin{array}{l}\text { Division } \\
(03 / 2014)\end{array}$ & 9 & $5(55.6)$ & $3(33.0)$ & $1(11.1)$ \\
\hline \multirow{3}{*}{ 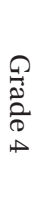 } & \begin{tabular}{|l} 
Volumes \\
$(10 / 2014)$
\end{tabular} & 7 & $4(57.1)$ & $2(28.6)$ & $1(14.3)$ \\
\hline & $\begin{array}{l}\text { Triangles } \\
(11 / 2014)\end{array}$ & 5 & $0(0)$ & $5(100)$ & $0(0)$ \\
\hline & $\begin{array}{l}\text { Quadrilaterals } \\
(04 / 2015)\end{array}$ & 5 & $0(0)$ & $4(80.0)$ & $1(20.0)$ \\
\hline
\end{tabular}

Source: Author's elaboration (2017).

\section{Quality of Argumentation Students Made}

The quality of argumentation from grade 3 to grade 4 was identified as the following features. First, the accuracy of warrants and the completeness of the components were enhanced compared to the other components (see Table 4). Second, the third-grade students' argumentations were not complete, even though they were able to formulate various conjectures. We identified four types of conjectures by checking their correctness. The conjectures in the first type grade 3 students made were mostly correct, but they did not rely on existing cases. Those in the second type were occasionally incorrect, even relying on existing cases. Those in the third type were true for the existing cases but not for all cases. The conjectures in the fourth type were always true for all cases, leading to the conclusion.

The conjectures the third-grade students initially formulated were not supported by warrants and without rebuttals against false conjectures ( 25 frequencies in Level 1 in the warrants column and 0 frequency in Level 2 and 3 in the rebuttals column), whereas their argumentations they developed in the fourth grade were getting used to accompanying a conjecture with a warrant, and both were relevant to mathematical properties (37 frequencies in Level 3 in the warrants column).

Educação \& Realidade, Porto Alegre, v. 43, n. 3, p. 1171-1192, July/Sept. 2018.1185 


\section{Table 4 - Frequencies of the Quality of Argumentation by Grade and Level}

\begin{tabular}{|c|c|c|c|c|c|c|c|c|c|c|c|c|c|c|c|c|}
\hline \multirow[t]{2}{*}{ Levels } & \multicolumn{4}{|c|}{$\begin{array}{l}\text { Accuracy of the } \\
\text { warrants }\end{array}$} & \multicolumn{4}{|c|}{$\begin{array}{l}\text { Types of } \\
\text { rebuttals }\end{array}$} & \multicolumn{4}{|c|}{$\begin{array}{l}\text { Completeness } \\
\text { of the compo- } \\
\text { nents }\end{array}$} & \multicolumn{4}{|c|}{$\begin{array}{l}\text { Validity of the } \\
\text { initial claims }\end{array}$} \\
\hline & 0 & 1 & 2 & 3 & 0 & 1 & 2 & 3 & 0 & 1 & 2 & 3 & 0 & 1 & 2 & 3 \\
\hline Grade 3 & 1 & 25 & 6 & 3 & 0 & 2 & 0 & 0 & 23 & 34 & 8 & 2 & 2 & 13 & 1 & 3 \\
\hline Grade 4 & 0 & 13 & 28 & 37 & 1 & 5 & 4 & 1 & 9 & 14 & 14 & 4 & 17 & 1 & 7 & 7 \\
\hline Total & 1 & 38 & 34 & 40 & 1 & 7 & 4 & 1 & 32 & 48 & 22 & 6 & 19 & 14 & 8 & 10 \\
\hline
\end{tabular}

The students in grade 4 not only gave more warrants, but also gave more valid ones than those did in grade 3 (see Table 4). In grade 4, their prior knowledge became the source of their warrants, but their warrants were also developed into plausible or valid level from irrelevant level; this was evidenced by the increase in frequencies of the initial claim column at Level 3 from 3 to 37 (see Table 4).

A conjecture with two warrants and one rebuttal as an example in Figure 4 was based on the following episode in grade 3 teaching: Jing asked students a question ( $\mathrm{T}_{1}^{\prime}$ ) (line 35$)$ to initiate a discussion. A conjecture $\left(\mathrm{S}_{1}\right)$ made by Group 2 was that The remainder of the division is 0 . It was accompanied by a warrant (Ws $)$ (line 36$)$. However, the conjecture $\mathrm{S}_{1}$ was immediately refuted by the group $\left(\mathrm{R}_{\mathrm{S} 1}\right)$ (line 36$)$. Therefore, the students realized that the conjecture $S_{1}$ could not be generalized to all cases. This refutation was not about the conjecture being false; instead, it showed that it could not be generalized. The students' warrant for refutation was some of the divisions of whole numbers might have a remainder. $\left(\mathrm{W}_{\mathrm{S} 2}\right)($ line 40$)$.

Figure 4-Argumentation Stream AS1 Drawing from the Topic of Division

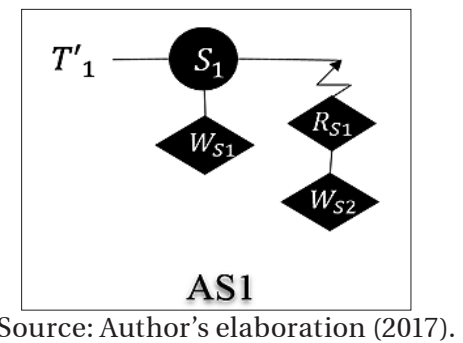

$35 \mathrm{~T}$ : Which of the conjectures from your groups cannot be true for more cases? $\left(\mathrm{T}_{1}\right)$

36 S: Group 2. [The left of the division is $0 .(\mathrm{S} 1)]$. $\left(\mathrm{R}_{\mathrm{SI}}\right)$

The six number sentences of division displayed on the worksheet $\left(\mathrm{W}_{\mathrm{S} 1}\right)$.

$37 \mathrm{~T}$ : What does it mean by without the remainder?

38 S: 0.

$39 \mathrm{~T}$ : Why are you not assured that the conjecture from this group is true? $40 \mathrm{~S}$ : Because some of the divisions of whole numbers might have a remainder $\left(\mathrm{W}_{\mathrm{S} 2}\right)$.

1186 Educação \& Realidade, Porto Alegre, v. 43, n. 3, p. 1171-1192, July/Sept. 2018. 
Lin

Figure 5 - Five Methods Students used for Justifying the Sum of Angles in a Triangle is $180^{\circ}$

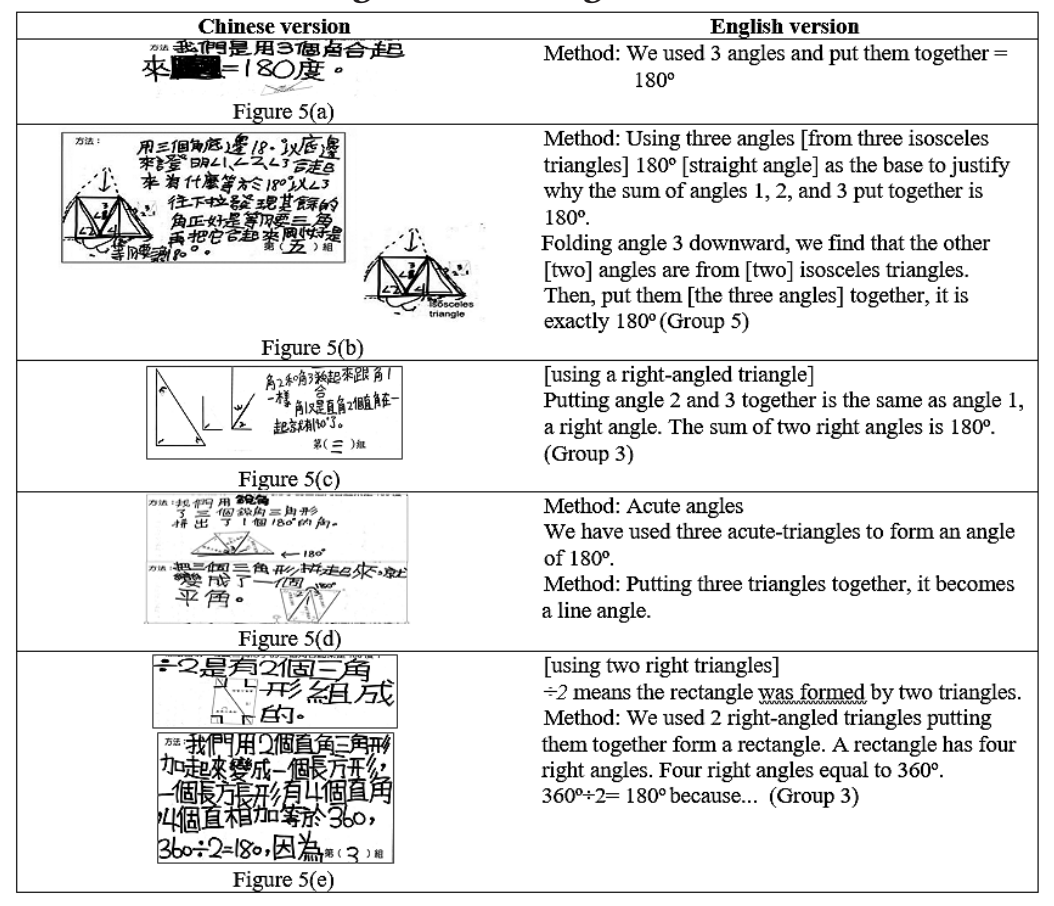

Source: Author's elaboration (2017).

The fourth-grade students justified that the sum of three angles in a triangle is $180^{\circ}$ through five methods (see Figure 5). The key idea of the justification displayed in the Figures 5(a), 5(b), 5(c), and 5(d) was putting the three angles together to form a line angle of $180^{\circ}$, whereas Figure 5(e) shows their use of the idea 4 right angles in a rectangle is $360^{\circ}$. However, the three angles in Figure 5(a) to 5(d) came from different triangles. The three angles for forming a line angle in 5(a) and $5(\mathrm{~b})$ were cut or folded in a triangle, whereas each of the three angles in Figure 5(d) was from three different triangles. Various triangles were used in different groups to justify the truth of the conjecture. The two complementary angles in a right triangle were formed into a right angle, as shown in Figure 5(c).

The justification displayed in Figure 5(e) was a deductive reasoning, relying on students' prior knowledge including a right angle with $90^{\circ}$, a rectangle with 4 right angles, and two congruent right triangles forming a rectangle. The students' prior knowledge was used in the warrants and backings for justifying the sum of three angles in any triangle is $180^{\circ}$.

\section{Discussions and Implications}

We have reported the major findings in this study on developing students' argumentation via conjecturing with scaffolding or question-

Educação \& Realidade, Porto Alegre, v. 43, n. 3, p. 1171-1192, July/Sept. 2018.1187 
ing by the teacher in a classroom from grade 3 to grade 4 . The results indicated four features of the nature of conjecturing and argumentation in the classroom. First, conjecturing appeared to be a potentially appropriate approach for developing students' argumentation in primary classrooms. For instance, as students engaging in the stage of generalizing the conjectures, a division is generally not necessarily making numbers smaller. When it is restricted to the integers, then a division must be making numbers smaller. A qualifier is involved in the process of generalizing.

Second, argumentative discourse has been enhanced for argumentation from grade 3 to grade 4 . The improvement of argumentation included the conjectures which shifted toward being supported with warrants and backings from those without warrants; the warrants also shifted toward being valid from being non-valid. The progress of argumentation in grades 3 and 4 is possibly attributed to the following factors: students' mathematical knowledge, experience of argumentation and conjecturing; teacher's expertise and experiences; questioning; tasks design; conjecturing as an instructional approach.

Students' mathematical knowledge gradually increased from grade 3 up to grade 4 , and so did their acquired experience of conjecturing and argumentation through practice in regular teaching. The expertise of teaching argumentation developed through practices played a key role in initiating and sustaining change of argumentation. Teacher's questioning also enabled us to identify the question types used in each stage of conjecturing that enabled the students' argumentation to proceed. The results of this study were consistent with those in Keith's (2006) study that questioning contributed to students' development of argumentation. However, questioning or question types involved in this study were more complex with different functions beyond Keith's questioning only in the contexts of correct or incorrect results. The questions were what did you discover?, Does each of your conjectures work for all cases? and how do you convince others that your conjectures are true?

One notable factor is the nature of the tasks because the guidelines of engaging in the conjecturing activities were concrete, tangible, and clear for embodying the essential ideas of a reform in mathematics teaching. The nature of tasks allowed students to have a great deal of time to learn from self-constructing cases, through formulating, validating, generalizing, and justifying their conjectures. According to Harel's (2008) intellectual need, students were more likely to be motivated by constructing their own cases than by the cases given by the teacher. This led them to engage in activities of conjecturing that argumentation takes place. The tasks involved in this study incorporating mathematical content without taking up extra hours, but as supplementary teaching materials brought about a change in the nature of classroom discourse and diminished teacher's fears in the highly tight schedules of teaching. The five stages of conjecturing embedded in the tasks not only enhanced students' argumentation but also contributed to solving their existing problems and addressing risk in textbooks. The 
risk in textbook was that mathematical properties were based on one or two supporting examples and without generalization and justification. Conjecturing also created the opportunity for the students to engage in justifying their claims by using deductive reasoning beyond the empirical arguments predominately used in textbooks.

It should be noted that the five stages of conjecturing via a finite set of discrete cases as an instructional approach played key roles not only for the development of students' argumentation but also for the teacher's acquisition of the knowledge for teaching argumentation. This study identified the rubrics of different levels of student argumentation processes helping teachers to transform knowledge of the argumentation process into classroom discourse. The result of this study indicates that the social norms of argumentation came naturally when students engaged in the five stages of conjecturing. For instance, students learned to organize the cases for identifying a pattern, learn to listen and talk, learn to find a counterexample to refute a disagreed claim or warrant.

Third, our work sought to develop with teachers' conjecturing tasks incorporated into regular mathematics instruction for argumentation to take place. As a result, this study contributes to the transition of conjecturing to argumentation. The rebuttals referred to in this study were not only against an incorrect conjecture and conjecturing not being true for all cases, but also against the disagreed warrants. Furthermore, there were four levels of rebuttals identified in this study. Students in grade 3 mostly refuted a conjecture without warrants, whereas when they were in grade 4 they sometimes refuted a conjecture with warrants and backings. For those mathematical topics they were more familiar with, they were sometimes able to refute a false rebuttal, e.g., recognizing triangles.

Finally, it is noted that our study contributes to the operative proof used by the participating primary students that was about the properties of geometry and the number patterns suggested by Wittmann (2009). For further studies, we suggest that teachers should provide students with early opportunities for them to engage in argumentation in regular instruction throughout the school years rather than in a shorttime intervention. Our findings are supported by the work of Osborne, Erduran and Simon (2004) and Kuhn (1991), indicating that enhancement in argumentation in grades 3 and 4 classrooms is possible if it is explicitly addressed and taught, such as via conjecturing incorporated into mathematics instruction.

Received on October 1st, 2017 Approved on November 3rd, 2017

Educação \& Realidade, Porto Alegre, v. 43, n. 3, p. 1171-1192, July/Sept. 2018.1189 
The Development of Students' Mathematical Argumentation in a Primary Classroom

\section{Note}

1 Acknowledgements: This article is based on work supported by the Ministry of Science and Technology of Taiwan under grant No. MOST 103-2517-S-134-001 -MY3. Any opinions, findings, conclusions, or recommendations expressed in this paper are those of the author and do not necessarily reflect the views of the MOST. The author would like to thank all of the teachers participating the study. The author thanks for anonymous for their suggestion for strengthening this paper.

\section{References}

BARKAI, Ruth; TSAMIR, Pessia; TIROSH, Dina; DREYFUS, Tommy. Proving or Refuting Arithmetic Claims: the case of elementary school teachers. In: COCKBURN, Anne; NARDI, Elena (Ed.). Proceedings of the $26^{\text {th }}$ Annual Conference of the International Group for the Psychology of Mathematics Education: volume 2. Norwich: University of East Anglia, 2002. P. 57-64.

CAÑADAS, María Consuelo et al. The Conjecturing Process: perspectives in theory and implications in practice. Journal of Teaching and Learning, Ontario, v. 5, n. 1, p. 55-72, 2007.

CAÑADAS, María Consuelo; CASTRO, Encarnación. A Proposal of Categorisation for Analysing Inductive Reasoning. In: CONGRESS OF THE EUROPEAN SOCIETY FOR RESEARCH IN MATHEMATICS EDUCATION, 4., 2005, San Feliu de Guixols. Proceedings... San Feliu de Guixols, Spain: 2005. P. 401-408.

COMMON CORE STATE STANDARDS INITIATIVE. Common Core State Standards for Mathematics. Washington, DC: National Governors Association Center for Best Practices and the Council of Chief State School Officers, 2010.

GABEL, Mika; DREYFUS, Tommy. The Flow of Proof: the example of Euclidean algorithm. In: LINDMEIER, Anke; HEINZE, Aiso (Ed.). Proceedings of the $37^{\text {th }}$ Conference of the International Group for the Psychology of Mathematics Education: volume 2. Kiel, Germany: PME, 2013. P. 321-328.

HANNA, Gila; VILLIERS, Michael de. Proof and Proving in Mathematics Education: the $19^{\text {th }}$ ICMI study. Dordrecht: Springer, 2012.

HAREL, Guershon; SOWDER, Larry. Toward Comprehensive Perspectives on the Learning and Teaching of Proof. In: LESTER, Frank (Ed.). Second Handbook of Research on Mathematics Teaching and Learning. Greenwich, CT: Information Age, 2007. P. 805-842.

INGLIS, Matthew; MEJIA-RAMOS, Juan Pablo; SIMPSON, Adrian. Modelling Mathematical Argumentation: the importance of qualification. Educational Studies in Mathematics, Dordrecht, v. 66, n. 1, p. 3-21, 2007.

KEITH, Annie. Mathematical Argument in a Second Grand Class: generating and justifying generalized statements about odd and even numbers. In: SMITH, Stephanie; SMITH, Marvin (Ed.). Teachers Engaged in Research: inquiry into mathematics classrooms, grades prek-2. Education Review, Arizona, 2006. P. 35-68.

KIM, Sungho; HAND, Brian. An Analysis of Argumentation Discourse Patterns in Elementary Teachers' Science Classroom Discussions. Journal of Science Teacher Education, Auburn, v. 26, n. 3, p. 221-236, 2015.

1190 Educação \& Realidade, Porto Alegre, v. 43, n. 3, p. 1171-1192, July/Sept. 2018. 
KNIPPING, Christine. A Method for Revealing Structures of Argumentations in Classroom Proving Processes. ZDM - The International Journal on Mathematics Education, Berlin, v. 40, n. 3, p. 427-447, 2008.

KO, Yi-Yin. Mathematics Teachers' Conceptions of Proof: implications for educational research. International Journal of Science and Mathematics Education, Dordrecht, v. 8, n. 6, p. 1109-1129, 2010.

KUHN, Deanna. The Skills of Argument. New York: Cambridge University Press, 1991.

LIN, Pi-Jen; TSAI, Wen-Huan. Enhancing Students' Mathematical Conjecturing and Justification in Third-Grade Classrooms: the sum of even/odd numbers. Journal of Mathematics Education, Irvine, v. 9, n. 1, p. 1-15, 2016.

MAHER, Carolyn. Children's Reasoning: discovering the idea of mathematical proof. In: STYLIANOU, Despina; BLANTON, Maria; KNUTH, Eric (Ed.). Teaching and Learning Proof across the Grades: a k-16 perspective. New York: Routledge \& National Council of Teachers of Mathematics, 2011. P. 120-132.

MAHER, Carolyn; MARTINO, Amy. The Development of the Idea of Mathematical Proof: a 5-year case study. Journal for Research in Mathematics Education, Reston, v. 27, n. 2, p. 194-214, 1996.

MAKAR, Katie; BAKKER, Arthur; BEN-ZVI, Dani. Scaffolding Norms of Argumentation-Based Inquiry in a Primary Mathematics Classroom. ZDM - Mathematics Education, Berlin, v. 47, n. 7, p. 1107-1120, 2015.

MASON, John; BURTON, Leone; STACEY, Kaye. Thinking Mathematically. Boston: Addison-Wesley, 1987.

NATIONAL COUNCIL OF TEACHERS OF MATHEMATICS. Principles and Standards for School Mathematics. Reston, VA: NCTM, 2000.

OSBORNE, Jonathan; ERDURAN, Sibel; SIMON, Shirley. Enhancing the Quality of Argument in School Science. Journal of Research in Science Teaching, New York, v. 41, n. 10, p. 994-1020, 2004.

PEDEMONTE, Bettina. How Can the Relationship between Argumentation and Proof be Analyzed? Educational Studies in Mathematics, Dordrecht, v. 66, n. 1, p. 23-41, 2007.

PÓLYA, George. Mathematics and Plausible Reasoning. 2. ed. Princeton, NJ: Princeton University Press, 1968.

REID, David; ZACK, Vicki. Aspects of Teaching Proving in Upper Elementary School. In: STYLIANOU, Despina; BLANTON, Maria; KNUTH, Eric (Ed.). Teaching and Learning Proof across the Grades: a k-16 perspective. New York: Routledge; National Council of Teachers of Mathematics, 2011. P. 133-145.

SCHIFTER, Deborah. Representation-Based Proof in the Elementary Grades. In: STYLIANOU, Despina; BLANTON, Maria; KNUTH, Eric (Ed.). Teaching and Learning Proof across the Grades: a k-16 perspective. New York: Routledge \& National Council of Teachers of Mathematics, 2011. P. 71-86.

STYLIANIDES, Gabriel. Reasoning-and-Proving in School Mathematics Textbooks. Mathematical Thinking and Learning, Mahwah, v. 11, n. 4, p. 258-288, 2009.

STYLIANIDES, Andreas; BIEDA, Kristen; MORSELLI, Francesca. Proof and Argumentation in Mathematics Education Research. In: GUTIÉRREZ, Ángel; LEDER, Gilah; BOERO, Paolo (Ed.). Second Handbook of Research on the Psychology of Mathematics Education: the journey continues. Rotterdam, The Netherlands: Sense Publishers, 2016. P. 315-351.

Educação \& Realidade, Porto Alegre, v. 43, n. 3, p. 1171-1192, July/Sept. 2018.1191 
STYLIANIDES, Gabriel; STYLIANIDES, Andreas; PHILIPPOU, George. Preservice Teachers' Knowledge of Proof by Mathematical Induction. Journal of Mathematics Teachers Education, Dordrecht, v. 10, n. 3, p. 145-166, 2007.

STYLIANOU, Despina; BLANTON, Maria; KNUTH, Eric (Ed.). Teaching and Learning Proof across the Grades: a k-16 perspective. New York: Routledge; National Council of Teachers of Mathematics, 2011.

TOULMIN, Stephen. The Uses of Argument. Cambridge, England: Cambridge University Press, 1958.

WITTMANN, Erich. Operative Proof in Elementary Mathematics. In: LIN, FouLai; HSIEH, Feng-Jui; HANNA, Gila; VILLIERS, Michael de (Eds.). Proof and Proving in Mathematics Education: ICMI study 19 conference proceedings: volume 2. Taipei: Taiwan Normal University, 2009. P. 251-256.

YACKEL, Erna; HANNA, Gila. Reasoning and Proof. In: KILPATRICK, Jeremy; MARTIN, Gary; SCHIFTER, Deborah (Ed.). A Research Companion to Principles and Standards for School Mathematics. Reston, VA: National Council of Teachers of Mathematics, 2003. P. 22-44.

Pi-Jen Lin is a professor of the Graduate Institute of Mathematics and Science Education, Tsing Hua University of Taiwan. She has been a member of the International program committees of the International group of Psychology of Mathematics Education (PME).

E-mail: linpj@mx.nthu.edu.tw

This is an open-access article distributed under the terms of the Creative Commons Attribution License 4.0 International. Available at: <http://creativecommons.org/licenses/by/4.0>. 